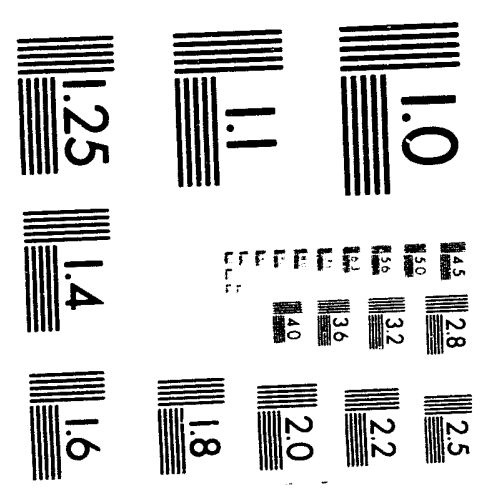



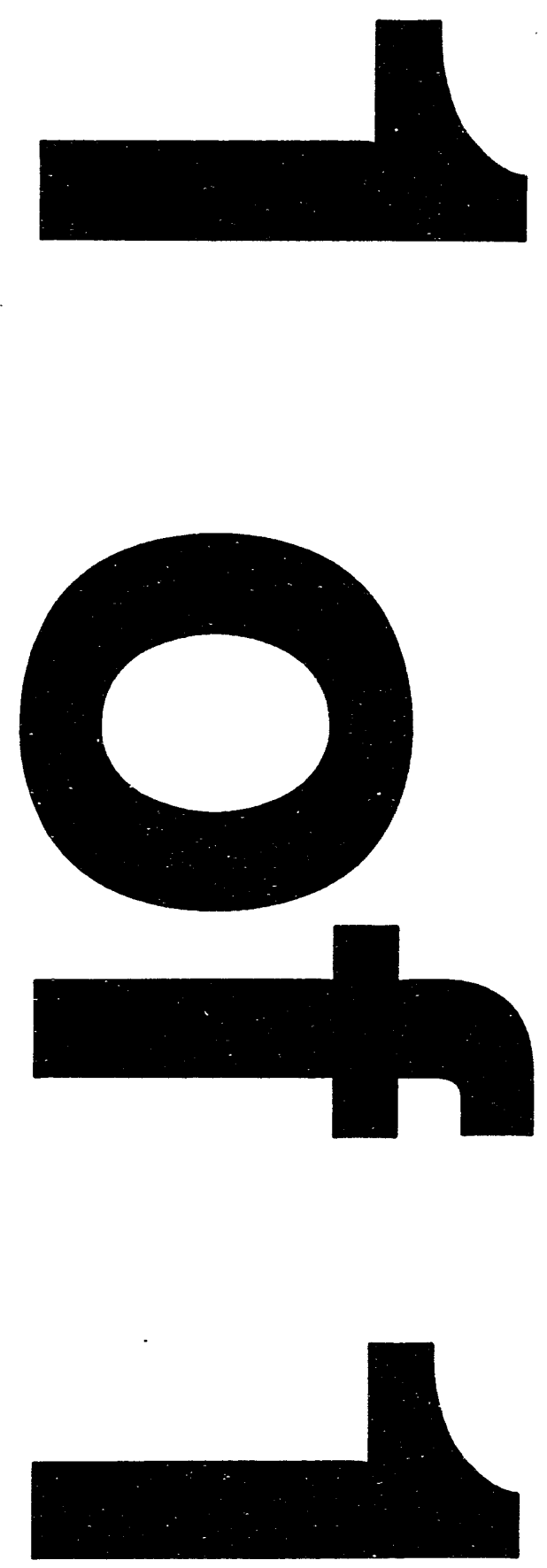


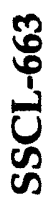

SSCL-663

February 1994

Distribution Category: 400

R. Meinke

N. Mokhov

D. Orth

Radiation Shielding

B. Parker

for the Super Collider

West Utility Region

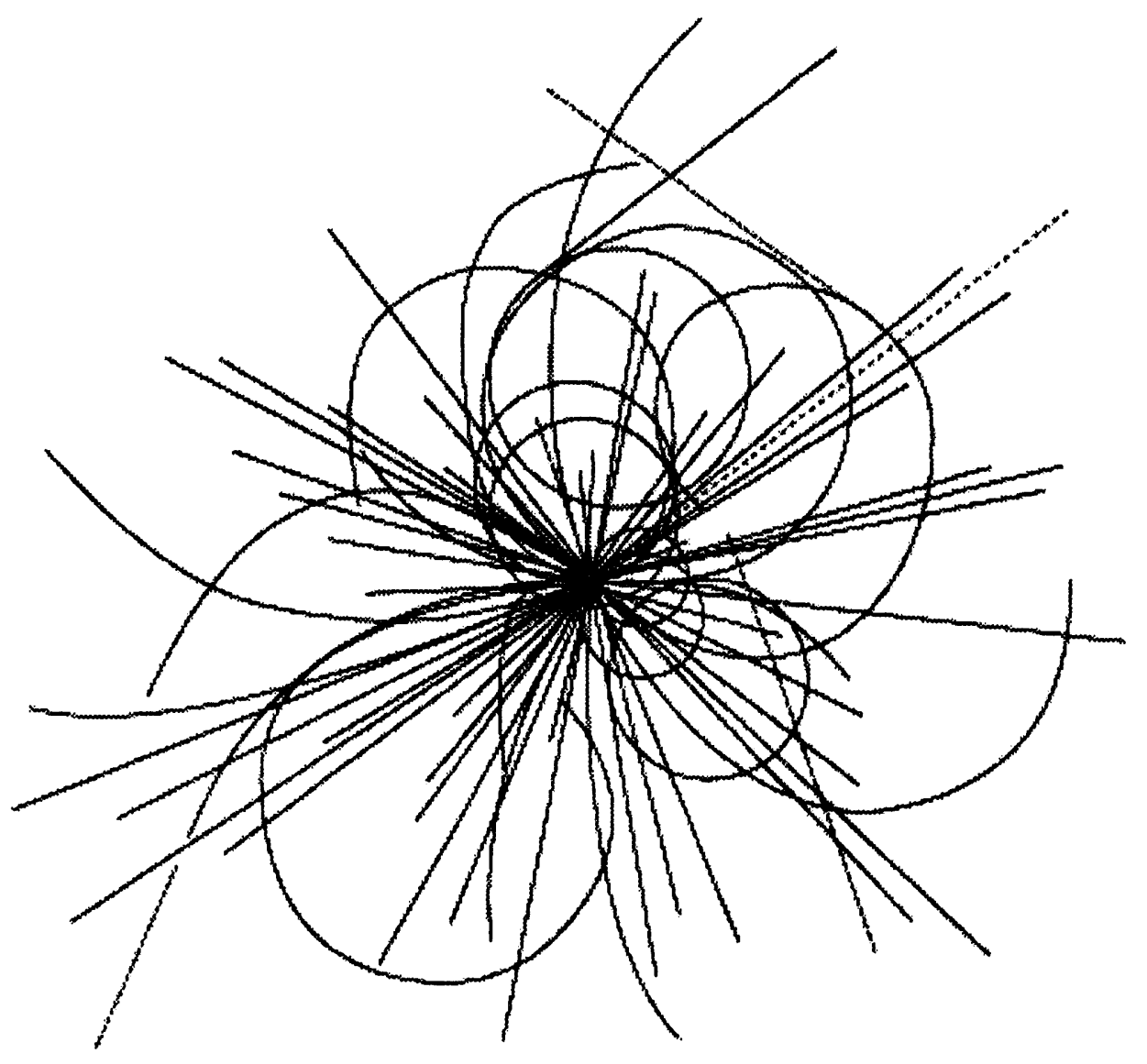

D. Plant

\section{Superconducting Super Collider Laboratory}




\section{Disclaimer Notice}

This repon was prepared as an account of work sponsored by an agency of Hie United States Govemment. Neither the United States Government or any agency thereof, nor any of their employees, makes any warranty, express or implled, or assumes any logal liablitity or responsibility for the accuracy, completeness, or usefulness of any information, apparatus, product, or process disclosed. or represents that its use would not infringe privately owned rights. Reference herein to any specitic commercial product, process, or service by trade name, trademark, manufacturer, or otherwise, does not necessarily consttute or imply its endorsement, recommendation, or favoring by the United States Government or any agency thereor. The views and opinions of authors expressed herein do not necessarily state or reflect those of the United States Govemment or any agency thereot. 
SSCL-663

\title{
Radiation Shielding for the Super Collider West Utility Region
}

\author{
R. Meinke, N. Mokhov, D. Orth, B. Parker, and D. Plant
}

Superconducting Super Collider Laboratory*

2550 Beckleymeade Ave.

Dallas, TX 75237 USA

February 1994

*Operated by the Universities Research Association, Inc., for the U.S. Department of Energy under Contract No. DE-AC35-89ER40486. 


\title{
Radiation Shielding for the Super Collider West Utility Region
}

\author{
R. Meinke, N. Mokhov, D. Orth, B. Parker, and D. Plant
}

\begin{abstract}
Shielding considerations in the $20 \times 20$-TeV Superconducting Super Collider are strongly correlated with detailed machine specifics in the various accelerator sections. The West Utility, the most complex area of the Collider, concentrates all the major accelerator subsystems in a single area. The beam loss rate and associated radiation levels in this region are anticipated to be quite high, and massive radiation shielding is therefore required to protect personnel, Collider components, and the environment. The challenging task of simultaneously optimizing accelerator design and radiation shielding, both of which are strongly influenced by subsystem design details, requires the integration of several complex simulation codes. To this end we have performed exhaustive hadronic shower simulations with the MARS12 program; detailed accelerator lattice and optics optimization via the SYNCH, MAD, and MAGIC codes; and extensive 3-D configuration modeling of the accelerator tunnel and subsystems geometries. Our technique and the non-trivial results from such a combined approach are presented here. An integrated procedure is found invaluable in developing cost-effective radiation shielding solutions.
\end{abstract}




\subsection{INTRODUCTION}

The Collider ${ }^{1}$ section of the Superconducting Super Collider (SSC) consists of two superconducting magnet rings, one on top of the other, with circumferences of $87 \mathrm{~km}$, housed in an underground tunnel. The machine lattice is composed of two arcs, which bend the beam around, and two utility straight sections connecting the arcs. Experiments can be accomplished in 2 to 4 interaction regions, which are located in the East and West interaction straight sections. Each ring receives a $2-\mathrm{TeV} / \mathrm{c}$ beam with an intensity of $1.3 \times 10^{14}$ protons from the High Energy Booster (HEB) and accelerates it to $20 \mathrm{TeV} / \mathrm{c}$. The plan for upgrades anticipates a 10-fold increase in luminosity, which corresponds to about a factor of 3 increase in beam intensity.

The center of the West Utility region is one of the most complex regions of the SSC. ${ }^{2,3}$ Concentrated in this single "warm" region, the West Utility Straight Section (WUSS), are all of the technical components necessary for getting the beam into and out of the main Collider accelerator (beam injection, tune-up, and abort subsystems); all of the radio frequency ( $\mathrm{rf}$ ) power equipment needed to accelerate the beam; beam diagnostics and damping subsystems; and the main components of the beam scraper system..

The many diverse subsystems found in the WUSS lead to a complex underground structure configuration. Figure 1 shows a schematic of the underground complex of tunnels and galleries that are required. Structures are marked in this figure according to the Collider half cell numbering scheme. In the WUSS the rings lie in a single tunnel located approximately $60 \mathrm{~m}$ below grade. The HEB is in a separate tunnel $14 \mathrm{~m}$ above the Collider. Beam transfer line tunnels from the HEB to the Collider cross in a "bowtie configuration" about the N132 central symmetry point. At N130 and N135 there are shafts that are shared for access to both the HEB and the Collider. The if cavities for both Collider rings are at N139. In order to feed rf power to these cavities four to six 2-m-ID shafts, offset from the Collider tunnel, are required for wave guides from klystrons on the surface. Also, a series of $20-\mathrm{cm}$-ID penetrations from the surface are provided at $\mathrm{N} 127$ and $\mathrm{N} 139$ for injection kicker power cables. Collider side galleries are provided at N130, N132, and N135 for abort system components. Due to the complexity of the WUSS, it was necessary to build a 3-D computer representation of the region for both radiation analyses and interference processing.

Elevation view: HEB-Collider bow tie region

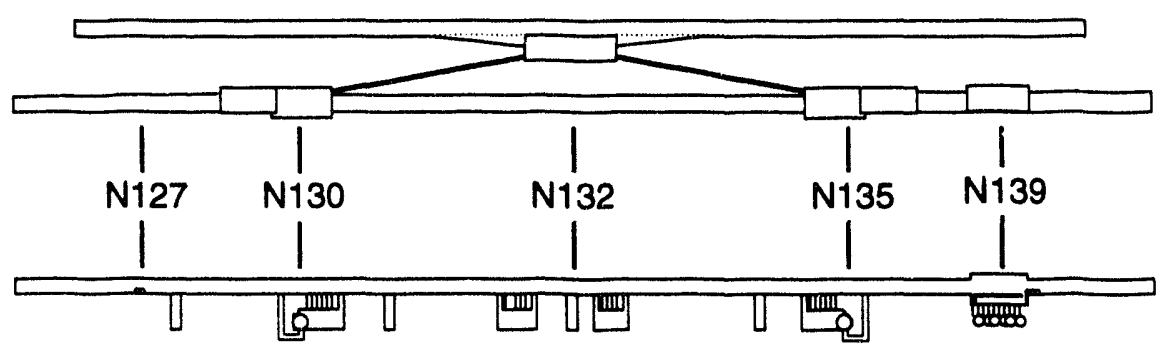

Plan view: Collider West Utility niches, galleries, and shafts

Not to scale

TIP-05346

Figure 1. Collider West UtIllty, schematlc view.

\subsection{BEAM LOSS AND RADIATION LIMITS}

Due to $p p$-collisions at the interaction points, beam-gas scattering, various instabilities, magnetic field errors, and beam halo scraping, a fraction of the beams will be lost in the Collider and will irradiate accelerator components. A reliable beam scraper/collimator system is required to protect accelerator equipment against this irradiation, to SL. tain acceptable background conditions in the interaction regions for the physics experiments, and to minimize the radiation exposure of personnel working in the tunnel (while 
accelerator is off), in the service buildings, and to the environment in general. ${ }^{4} \mathrm{~A}$ beam collimation system (BCS), situated in the WUSS, utilizes components of the beam abort system. The BCS consists of horizontal and vertical scrapers and a set of collimators that intercept beam particles with excessive betatron amplitudes. While protecting the rest of the machine, the BCS generates significant radiation levels in this area (see Table 1).

TABLE 1. WEST UTILITY ANNUAL BEAM LOSS.

\begin{tabular}{|l|l|l|}
\hline \multicolumn{1}{|c|}{ Event } & \multicolumn{1}{c|}{ Baseline } & \multicolumn{1}{c|}{ Upgrade } \\
\hline Beam-gas (p/m/yr) & $2.2 \times 10^{11}$ & $6.6 \times 10^{11}$ \\
\hline Scrapers (p/yr) & $7.2 \times 10^{15}$ & $1.0 \times 10^{16}$ \\
\hline Collimators $(p / y r)$ & $(3-6) \times 10^{14}$ & $(0.5-1) \times 10^{15}$ \\
\hline Beam abort (p/yr) & $6.5 \times 10^{16}$ & $2.0 \times 10^{17}$ \\
\hline Accident (p/accident) & $1.3 \times 10^{14}$ & $4.0 \times 10^{14}$ \\
\hline
\end{tabular}

As a result of primary interactions of beam particles with machine components, extensive hadronic cascades are developed in matter producing copious amounts of secondary particles, with the energy spectra extended from $\mathrm{TeV}$ energies down to thermal neutron energy $(\sim 0.025 \mathrm{eV})$. The corresponding radiation levels in the tunnel and on the surface could be extremely high without appropriate shielding.

The design of such shielding must ensure levels below those listed in Table 2. SSC Laboratory policy is that radiation design goals include the sum of all sources (direct, ingestion, and inhalation). The groundwater limit is applied to drinking water at $1 \mathrm{~m}$ distance from tunnel walls in saturation. The groundwater design goal is the driving criterion in determining the radiation shielding parameters for underground components.

TABLE 2. SSCL RADIATION DESIGN GOALS.

\begin{tabular}{|l|l|}
\hline \multicolumn{1}{|c|}{ Area } & Design Goal (mSv/yr) \\
\hline Off-Site Areas & 0.1 \\
\hline On-Site Open Areas & $0.2(0.1$ per accident) \\
\hline Controlled Areas & $2(1$ per accident) \\
\hline Air Activation & 0.001 \\
\hline Groundwater Activation & 0.04 \\
\hline
\end{tabular}

\subsection{CALCULATIONAL TOOLS}

Accelerator lattice and optics optimization of all 9 beamlines (1 HEB ring, 2 transfer lines, 2 tune-up lines, 2 Collider rings, and 2 Collider abort beamlines) was first carried out via the SYNCH, ${ }^{5} \mathrm{MAD},{ }^{6}$ and MAGIC ${ }^{7}$ codes. The resulting detailed lattice configurations were then incorporated into a 3-D computer model. The 3-D modeling of accelerator components and related support equipment was accomplished using MICROSTATION CAD software. An application was developed on top of the graphics engine to read data derived from the MAD survey output. Component type, magnetic length, coordinate positions, alignment angles, and tilt rotations present in the survey output were applied to a template library to create an accurate 3-D geometry of each component.

The completed model was then used for visualization, interference processing, and estimation of clearance between components. Video animation was also generated to more effectively communicate the issues related to design, installation, and maintenance of this complex region. The results from numerous design reviews were then fed back into the lattice configuration files, and the whole process was then iterated.

After each major design update, the configuration was used in simulations of all primary interactions of beam (source term); 3-D hadronic and electromagnetic cascades development; and muon and low-energy 
neutron transport in accelerator components, radiation shielding, tunnel, and shafts. These simulations were done with the MARS 12 code. ${ }^{8}$ This Monte Carlo code allows fast cascade simulation with modest memory requirements in complex geometries with composite materials, in the presence of arbitrary magnetic fields, with a variety of biasing, optimization, scoring, and statistics control options. If needed, the code can be coupled with the STRUCT code $^{9}$ for particle tracking in the whole accelerator lattice.

\subsection{LOCAL SHIELDING}

For a project of the scale of the SSC, local shielding around the "hot" objects is the most economical way to reach the radiation design goals. Shielding design involves a multistep procedure. First, a source term is studied in detail for the given lattice. Scraper and collimator efficiency is optimized at this stage. Then, the radiation shielding in all the "hot" regions required to meet the groundwater limit is calculated. Compact and cheap materials with good attenuation properties, such as steel and ordinary concrete, are considered. At a third stage, compatibility of the above shielding with the conventional construction and other accelerator components is studied via 3-D modeling. Finally, the optimization of shielding materials and configuration, as well as a reconsideration of the conventional facilities design, is iterated as needed. Figure 2 shows the shielding in the most occupied scraper region. Parameters of steel shielding are given in Table 3.

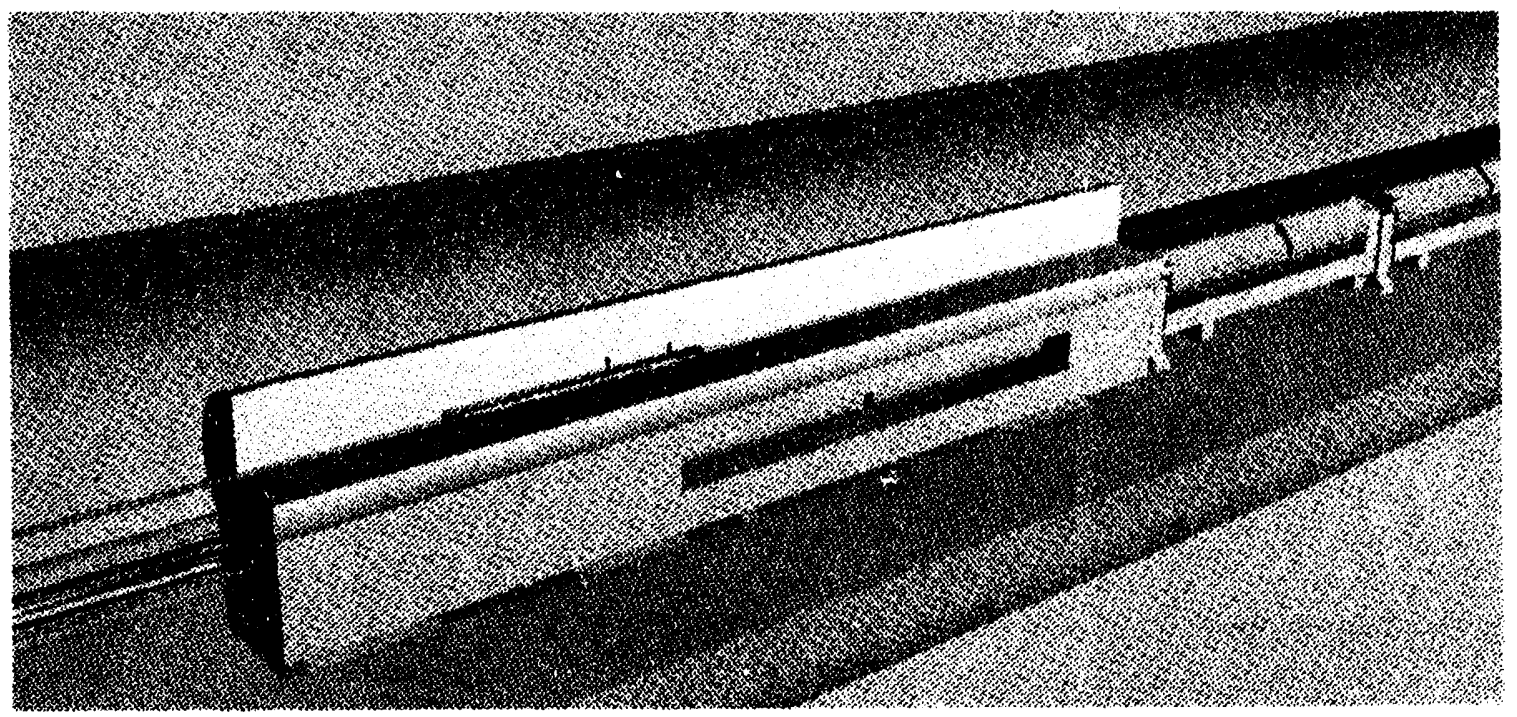

Figure 2. Radiation shielding in the scraper reglon.

TABLE 3. SHIELDING AROUND SOME WUSS COMPONENTS.

\begin{tabular}{|l|c|c|}
\hline \multicolumn{1}{|c|}{ Component } & Length $(\mathrm{m})$ & Thlcknes8 $(\mathrm{m})$ \\
\hline Scraper & 11.5 & 0.65 \\
\hline Beam Pipe & 20.0 & 0.50 \\
\hline Beam Pipe & 30.0 & 0.30 \\
\hline Shadow Lambertson & 5.0 & 0.35 \\
\hline Shadow Collimator & 5.0 & 0.50 \\
\hline Collimators & 4.5 & 0.35 \\
\hline
\end{tabular}




\subsection{HEB TO COLLIDER TRANSITION}

As already mentioned, the center of the WUSS is the most complex civil construction region of the Collider complex. It is here that the clockwise and counterclockwise beam transfer lines from the HEB descend $14 \mathrm{~m}$ to feed the top and bottom Collider rings. The region where the transfer line tunnels separate, cross, and then merge with the main Collider tunnel is called the bow tie region. Contrary to the original cathedral concept, ${ }^{1}$ the new concept, which resulted from our 3-D computer-aided design modeling studies, leaves more rock in place for better radiation shielding and requires less excavation for easier construction. To provide access to one machine while the other is on, the shielding between the HEB and the Collider has to meet a design goal of $1 \mathrm{mSv}$ for the worst-case catastrophic beam loss. The calculated thicknesses $d$ of such a shielding, assuming Austin Chalk or ordinary concrete as a material, are shown in Table 4 for the baseline and upgrade beam intensities. Maximal thickness for the actual mixture of Austin Chalk, Eagle Ford Shale, and concrete walls is equivalent to $6.4 \mathrm{~m}$.

TABLE 4. REQUIRED SHIELDING BETWEEN HEB AND COLLIDER.

\begin{tabular}{|l|c|c|c|}
\hline Access to & Accident in & Beam & $d\left(\mathrm{~g} / \mathrm{cm}^{2}\right)$ \\
\hline HEB & Collider & $1.3 \times 10^{14}$ & 1341 \\
& & $4.0 \times 10^{14}$ & 1447 \\
\hline Collider & HEB & $2.0 \times 10^{13}$ & 950 \\
& & $1.0 \times 10^{14}$ & 1100 \\
\hline
\end{tabular}

An essential feature of the new design is that we give up being able to drive a transport vehicle all the way down the slope from the HEB to the Collider. The new concept involves lowering magnets through a single common access point into effectively a basement sub-level of the HEB. With the new layout one does not have to cross over a magnet string in order to get to the transportation lane.

\subsection{SHAFTS AND NICHES}

A variety of access shafts have been designed to provide multi-purpose connections to the underground tunnel. The WUSS shafts are especially varied in purpose, shape, and size: from $20-\mathrm{cm}$ conduits for injection kicker cables to the N15 magnet delivery shaft with an $18 \times 9-\mathrm{m}$ opening. There are 198 niches in the Collider tunnel needed to house electronic equipment used to run the accelerator. Six of them are in the WUSS, in the region with increased radiation levels. The full-scale calculational studies of beam loss and cascade development in the accelerator components, and consequent radiation transport in the tunnel, underground facilities, and vertical shafts have been performed. 10,11

The MARS 12 calculations start with hadronic shower simulations in the lattice components. Two beamloss scenarios have been considered. To satisfy the SSCL radiation design goals, a really worst-case scenario was assumed: a quasi-instantaneous loss of the whole $20-\mathrm{TeV}$ proton beam on the beam pipe just upstream of the mouth of the horizontal connection to the shaft. This is applied to all the areas listed in Table 2. To study radiation dosage to the components, particularly electronics, accumulated values based on the expected "steady-state" beam loss over $25 \mathrm{yr}$ was taken into account. Loss of $10^{4}$ protons per meter per second in each of two Collider rings was assumed in these calculations as operational beam loss. Interactions of particles, escaping the accelerator components, and radiation transport in the tunnel and other conventional constructions, in their equipment, in adits, and in shielding walls are simulated with MARS12 code at the second stage. At the third stage, dose attenuation along the vertical shafts is calculated with the "universal curves," based on a fit of direct Monte Carlo calculations. 10,11

Figure 3 shows neutron energy spectra in the Collider tunnel at the entrance to any niche or adit, and behind concrete shielding walls. There are two basic constituents to the radiation at a tunnel: high-energy hadrons (E $>15 \mathrm{MeV}$ ) and low-energy neutrons. The first component, emitted from the magnets, should be 
absorbed by heavy materials, as solid steel or concrete walls. The low-energy neutrons, escaping from magnets, and also copiously generated in interactions of high-energy hadrons with facilities walls, equipment, and shielding, are better attenuated by materials with high hydrogen concentrations. To minimize the dose in the critical areas, high-energy hadrons must be intercepted as close as possible to their origin, with no straight vision of the source from the bottom of the vertical shaft.



Figure 3. Neutron energy spectra in the tunnel.

A "hammer-head" design was found to be very effective for all the utility, personnel, and ventilation shafts. A set of shielding walls was proposed to be installed in the adits of most of those shafts to provide radiation levels in the service buildings at the top below $1 \mathrm{mSv}$ per accident. The examples in WUSS are the rf shaft (Figure 4) and an electronics niche (Figure 5). The most practical shielding measure at magnet delivery shafts was found to be a concrete cap on top, 1.5-4.5-m thick (depending on the shaft depth), which keeps the dose below $0.1 \mathrm{mSv}$ per accident.

Each electronics niche needs a cooling system and a fire wall, and has to provide radiation protection for the electronics. A good solution is to install two walls from the floor to the ceiling in a labyrinth configuration (Figure 5). The simple, but not the cheapest, approach is to build the walls out of ordinary concrete. Neutron fluence attenuation curves are shown in Figure 6 for a niche with no walls, with two 1-ft-thick walls, and with two 2 -ft-thick walls. The three lines labeled for electronic hardware are the generally accepted numbers for reasonable risk exposure.

We found a way to combine all three needs of the niches into one multi-function wall. Most good attenuators for low-energy neutrons, like polyethylene, are combustible and are, therefore, unacceptable; however, water is an efficient moderator. So the solution was to use solid cinder blocks for the walls, followed by a meander of black pipe hooked to the cold-water distribution system. A shielding efficiency of the 2-ft cinder block wall, followed by the "water shielding," coincides with the $2 \times 1$-ft curve in Figure 6 for a small percentage of the dollars spent for concrete walls alone.

It was deemed desirable to be able to perform maintenance in either the HEB or the Collider with the other machine on, so radiation shielding walls are provided for in the transfer tunnels. Also, the commonuse shafts at N130 and N135 are connected in a "snorkel" configuration in order to prevent radiation from easily penetrating between the machines. 


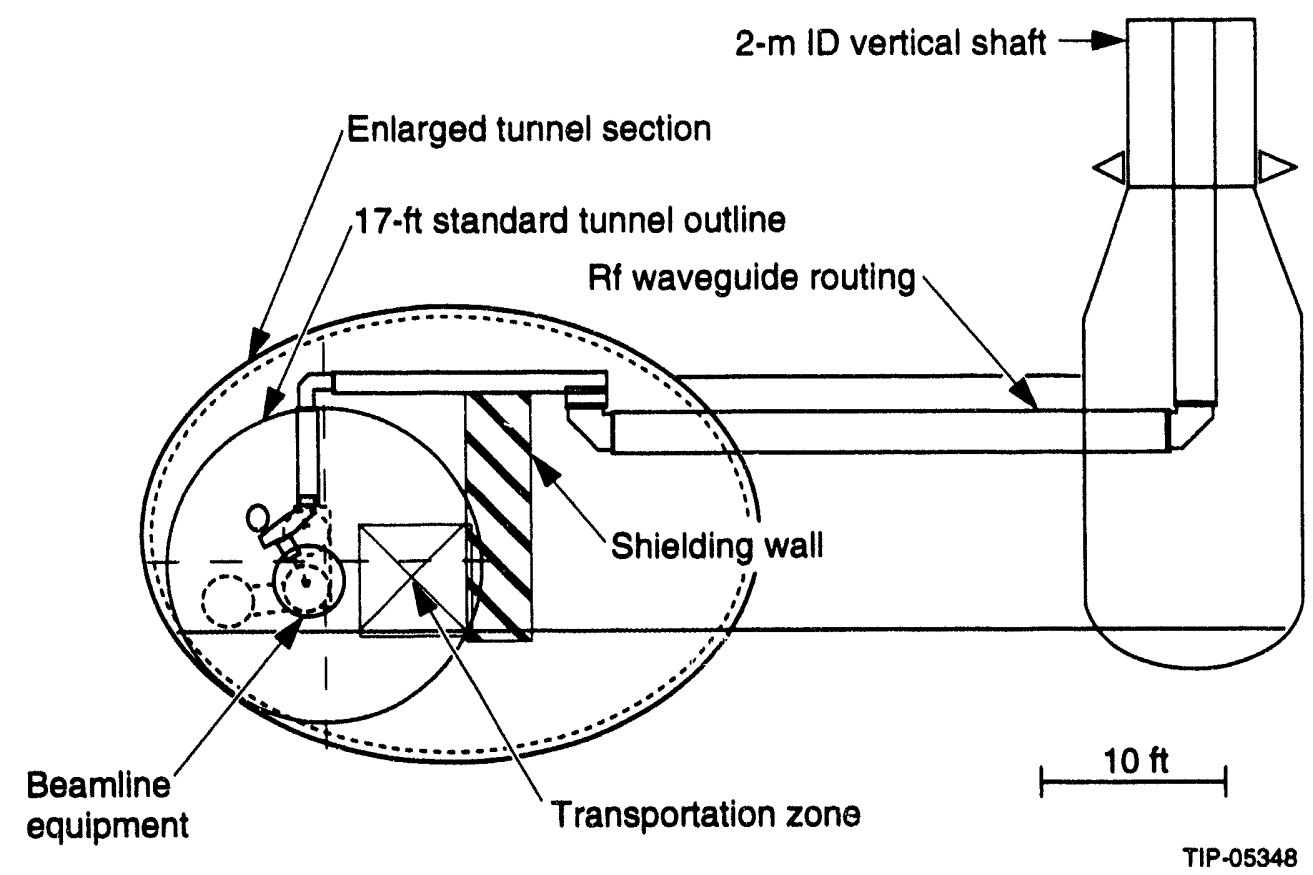

Figure 4. WUSS tunnel and if shaft cross sectlon.

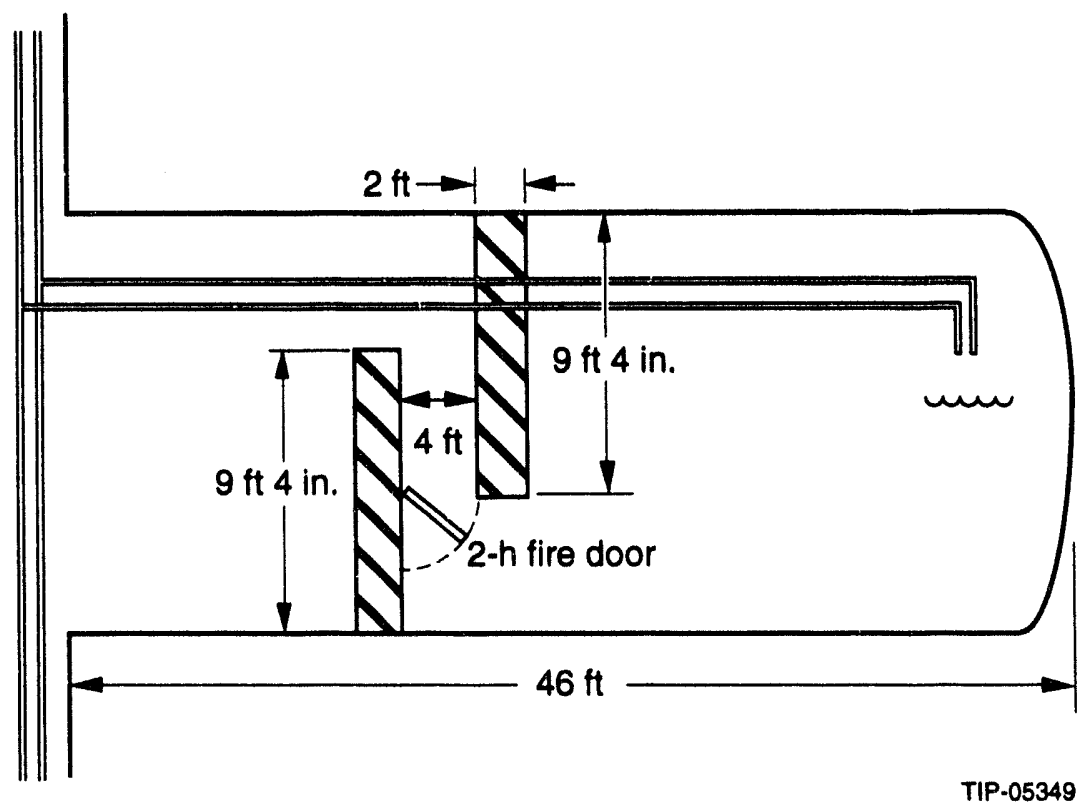

Flgure 5. Collider electronics niche, schematlc view. 


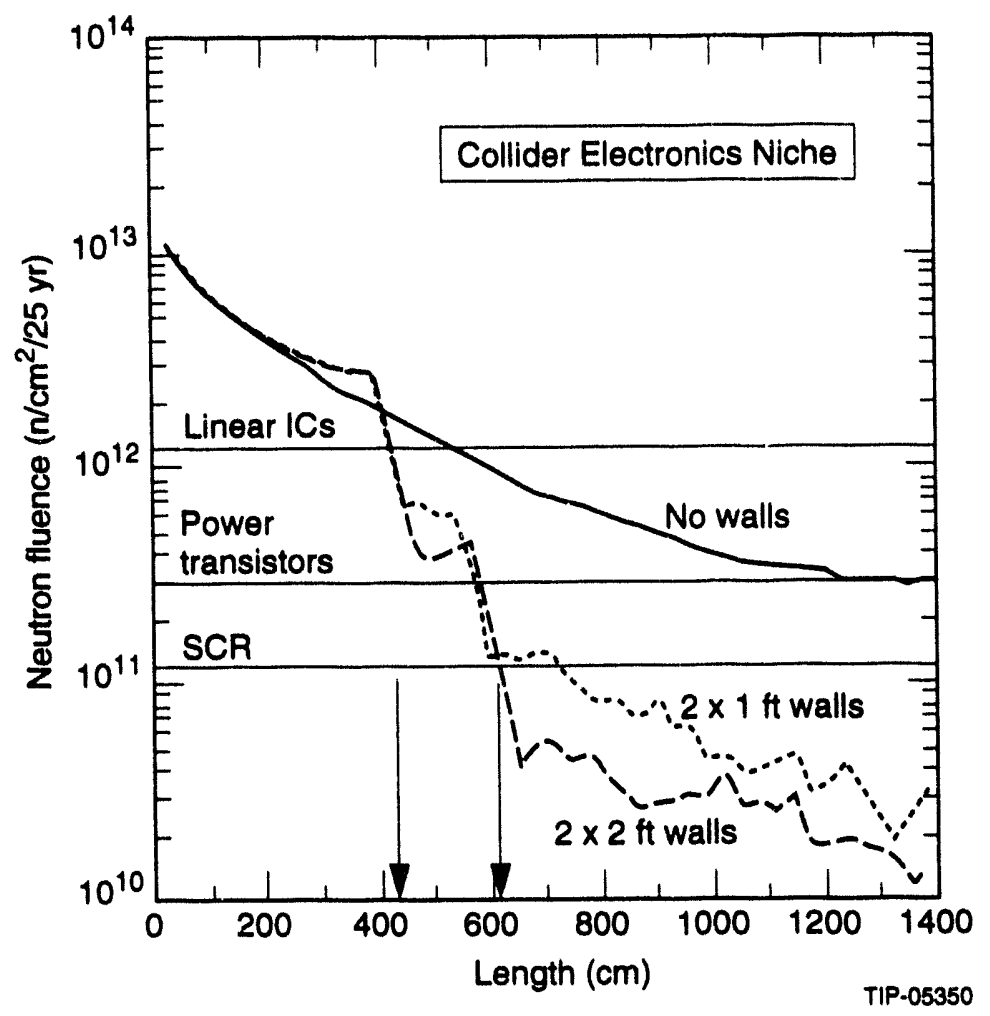

Figure 6. Neutron fluence attenuation in a nlche.

\subsection{BEAM BACKSTOP}

On request the beams are safely aborted in the external beam backstops. ${ }^{12}$ The backstops consist of central segmented graphite cores $1.8 \times 1.8 \times 8.0 \mathrm{~m}$, which are surrounded by a combination of iron and concrete for mass shielding. The configuration is shown in Figure 7. The backstop core must be robust enough to handle the $420 \mathrm{MJ}$ (equivalent to about $100 \mathrm{~kg}$ of TNT) of the nominal circulating primary beam energy and must be surrounded by enough mass shielding to ensure that groundwater irradiation remains within the guidelines. The transverse core size was chosen to accommodate the beam being spread or "painted" in a raster pattern on its front face, as generated by the beam abort system. The longitudinal extent of the graphite core is chosen to contain the peak energy deposition with sufficient margin. The raster pattern avoids damage to the core due to the extreme energy density of the beam. Hydrodynamic codes have been used to investigate various beam-painting failure modes; it was found that with the current configuration the energy deposition is contained with only irrelevant cracking of graphite over a small interior region of the core. ${ }^{13}$

The backstops are located in underground galleries, as shown in Figure 7. With the current design concept, access and emergency egress requirements from the backstop areas are met by the combination of travel along the separate abort beamline tunnels and via cross connections to the main Collider tunnel at the $\mathrm{N} 144$ (bottom ring backstop) and the N152 (top ring backstop) locations. Installation and maintenance of the backstops are through 5-m-ID shafts, which come off to this cross-connect in a T-configuration. We take advantage of the 35-m cross-connect tunnel length by placing the adit connection midway between the backstop gallery and the Collider tunnel. This placement gives the longest possible path for radiation from both sides to reach the surface. The cross connection corners are rounded for ease of construction and backstop installation. The cinder block shielding walls shown are assembled after backstop installation is complete. With this configuration only a relatively thin shaft plug is required at the surface. 


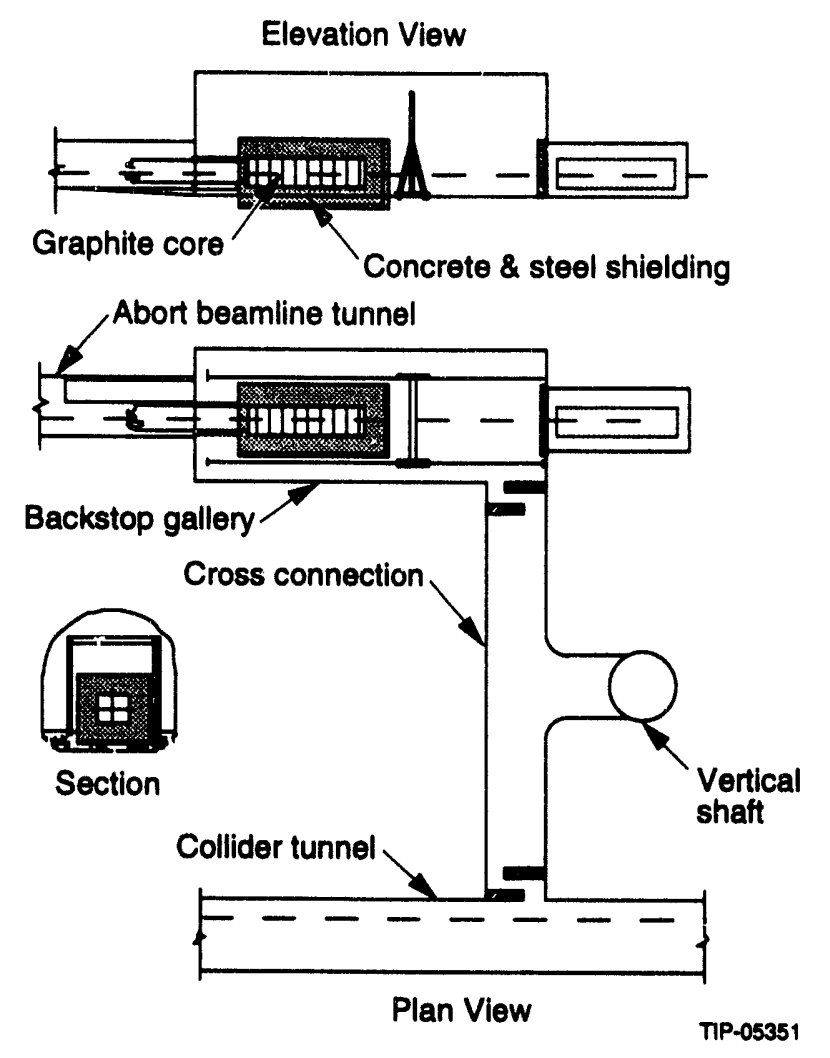

Figure 7. Collider beam backstop facility, schematic view.

\subsection{RESIDUAL RADIOACTIVATION}

Detailed calculations of radioactivation in the WUSS have been performed. The residual dose rate in saturation on the outer surfaces of the shielding and machine components right after shutdown are calculated to be $P_{c} \sim 0.5 \mathrm{mSv} / \mathrm{h}$. However, radiation doses on the insides of the scrapers and collimators are comparatively high, in a range of $P_{c} \sim 10-1000 \mathrm{mSv} / \mathrm{h}$. Therefore, some remote control and robotics will be required to handle those objects. Concerning cooling water, which removes several $\mathrm{MW}$ of heat, calculated dose rate at $30 \mathrm{~cm}$ from the pipe in a service building is well below the tolerable levels. For single catastrophic beam loss, a dose can be as high as $0.5 \mathrm{mSv}$ after a 1-min decay, and $0.04 \mathrm{mSv}$ after an 11-min decay time. For the upgrade intensity these numbers are 3 times higher, which might require some delay valve or a fence at $1 \mathrm{~m}$ from the pipe. In case of a water leak, radioactivity concentration is low; nevertheless, this water has to be collected and tested. Estimated dose due to air activation is close to the design goal for given layout. Uncontrolled radionuclide release is eliminated by an appropriate ventilation scheme and air dilution.

\subsection{CONCLUSIONS}

Radiation shielding has been carefully analyzed for the West Utility region of the Superconducting Super Collider. Different beam-loss scenarios have been considered to estimate radiation levels for expected operational modes and possible accidents. To come up with cost-effective solutions, it was necessary to simultaneously optimize the accelerator and shielding design. A rather detailed 3-D computer representation of the accelerator components and of all shielding was mandatory for this approach. Innovative new shielding designs, like cinder block walls covered by cooling water pipes, have been invented. The stringent radiation safety regulations imposed on the Laboratory have been met in all cases. 


\section{ACKNOWLEDGMENTS}

Many members of the SSCL Project Management Office and Conventional Construction Division staff, as well as the PB/MK team, have been involved in the design of the WUSS at various stages. The authors wish to thank especially J. Ives, T. Toohig, R. Molenaar, J. Shively, I. Baishev, J. Buil, A. Drozhdin, M. Popp, and R. Richardson. 


\section{REFERENCES}

1. "Site-Specific Conceptual Design of the Superconducting Super Collider," SSCL, (1990).

2. B. Parker, "Design Status Report on the Collider Utility Straight Insertions," SSCL-Preprint-326 (1993).

3. M. Butalla, B. Parker, D. Orth, A. Elioff, "Facility Modeling of West Utility Straight Tunnel Section," SSCL-Preprint-329 (1993).

4. M. Maslov, N. Mokhov, I. Yazynin, "The SSC Beam Scraper System," SSCL-484 (1991).

5. A.A. Garren, A.S. Kenney, E.D. Courant, A.D. Russell, M.J. Syphers, "SYNCH User's Guide," SSCL Report SSCL-MAN-0030 Rev. (1993).

6. "The MAD Program V8.1," CERN Report CERN/SL/90-13(AP).

7. M. J. Lee, W. W. Lee and L. C. Teng, "Magnet Insertion Code (MAGIC)," Fermilab Report TM-447 (1973).

8. N. Mokhov, "MARS12 Code System," Proc. SARE Workshop, Santa Fe, January 1993. See also N. Mokhov, Fermilab FN-509 (1989).

9. A. Drozhdin, I. Baishev, N. Mokhov, "The STRUCT Program User's Reference Manual," (1994) (unpublished).

10. I. Baishev, N. Mokhov, T. Toohig, "The SSC Access Shafts Calculationai Study," SSCL-496 (1991).

11. I. Baishev, N. Mokhov, "Firming Up the SSC Access Shafts Calculations," SSCL-521 (1992).

12. B. Parker, "On the Design of Beam Absorbers for the SSC," SSCL-430 (1991).

13. D. Wilson, C. Wingate, J. Goldstein, R. Godwin, and N. Mokhov, "Hydrodynamic Calculations of 20-TeV Beam Interactions with the SSC Beam Dump," IEEE Proc. 1993 Particle Accelerator Conf., Vol. 4, p. 3090 (1993). 

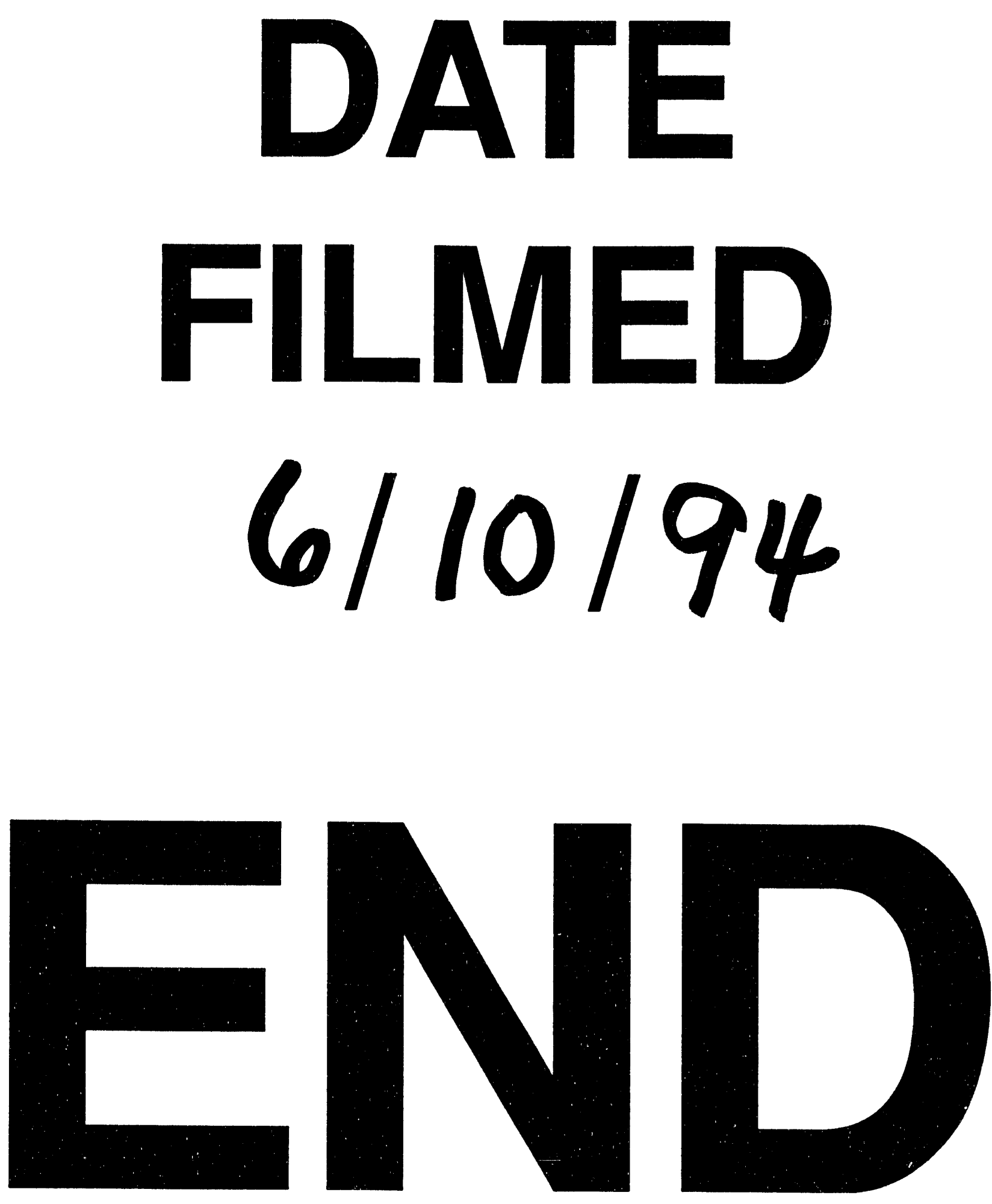
